\title{
Evolutions of Carpe Diem for learning design
}

Julie Usher, Sheila MacNeill, Linda Creanor

The University of Northampton, Glasgow Caledonian University

\begin{abstract}
This paper presents a comparative case study from two UK universities that contextualises their use of the Carpe Diem Learning Design methodology. The aim of the case study is not to share an evaluation of the Carpe Diem process per se, as both institutions are confident in the validity of the design process it scaffolds. Rather, it explores the different contexts, institutional drivers and evolutions of the original process in both institutions: supporting the development of online programmes at Glasgow Caledonian University and blended programmes through the CAleRO framework (Creating Aligned Interactive educational Resource Opportunities) at the University of Northampton. It then shares common challenges and opportunities; in particular the use of Carpe Diem to support open educational practice. The aim is to contribute to a continuing collaborative narrative about the processes involved in implementing and embedding a formal learning design process such as Carpe Diem.
\end{abstract}

Keywords: learning design, digital learning, open education practice

\section{Introduction}

As higher education (HE) evolves to take account of various internal and external drivers, the process of curriculum design is becoming increasingly important to learning and teaching practice (Conole, 2013). Many of these drivers, not least of which are student and employer expectations regarding digital capabilities, emphasise the need for the design of effective student-centred learning experiences, in or out of the classroom. By engaging academic staff teams in collaborative approaches to the design of these experiences, creativity and innovation - in learning, teaching and assessment - can be encouraged and the digital capabilities of both staff and students enhanced. 'Carpe Diem' (Salmon, 2013) is one such model, which provides a two-day structured workshop framework for a team-based approach to curriculum design.

Since its inception over fifteen years ago, Carpe Diem has been adopted and adapted by a number of institutions in the UK and Australia to support teaching staff in designing and redesigning courses (Conole and Wills, 2013; Dempster et al., 2012; Salmon and Wright, 2014). To demonstrate the flexibility of this approach, this case study will look at two examples from UK institutions: Glasgow Caledonian University, one of the pilot institutions for the original Carpe Diem process in 2002, and the University of Northampton, which joined the ADDER (Assessment \& Disciplines: Developing E-tivities Research) project in 2008 (Armellini and Aiyegbayo, 2010). This case study will review how each institution has contextualised the process, to align with specific institutional priorities, and explore the lessons learned so far through their experience of supporting course design. 


\section{Context}

\section{Example 1}

Glasgow Caledonian University (GCU) is a modern Scottish university with over 16,000 students. GCU was one of the pilot institutions for the original Carpe Diem process in 2002, when Professor Gilly Salmon, the originator of Carpe Diem, was appointed as visiting professor in the Caledonian Business School. At that time, the University was introducing a new VLE (Blackboard). This circumstance presented an ideal opportunity to engage colleagues in curriculum design to support the development of blended and online programmes. The outcomes were positive, building confidence among academics and encouraging creativity in learning design (Salmon et al., 2008). For the next few years, Carpe Diem continued to be used, primarily in the Business School, and also underpinned the re-design of assessment practices at GCU during the Re-Engineering Assessment Practices (REAP) project, funded by the Scottish Funding Council from 2005-7 as part of the e-learning transformation programme.

\section{Example 2}

The University of Northampton (UoN) is one of the youngest universities in the UK and has over 10,000 students. We adopted the Carpe Diem framework and began adapting it as 'CAleRO' (Creating Aligned Interactive educational Resource Opportunities), in 2008. Initially, the CAleRO workshop was adopted by subject teams involved in the pilot project, who developed pockets of good practice. It wasn't until the creation of our Institute of Learning and Teaching in 2012 that we began promoting it as our institutional approach to course design.

UoN is currently focused on an institutional curriculum change project, driven by our Learning and Teaching Plan and the move to our new "Waterside'1 campus in September 2018. The plan, which is informed both by research into effective pedagogy and by an increasing need to develop the digital literacies of students and staff, outlines our institutional commitment to 'active blended learning' (ABL) as the norm across all our taught programmes. Delivering on this means re-designing much of our learning and teaching as well as moving away from traditional lecture-based teaching to more small-group, interactive and student-centred approaches. CAleRO is a good fit for this strategy, because of the emphasis on "learner-centred, task-based learning design" and effective use of learning technologies it inherits from the Carpe Diem model (Armellini and Aiyegbayo, 2010).

\section{Implementation}

\section{Example 1}

At GCU in 2014, there was a renewed drive across the University to increase the number of fully online Masters-level programmes. In response to this, the central Blended Learning Team revisited the original Carpe Diem process and over the past three years has been developing it into a flexible learning design methodology supportively aligned to the strategic aims of the University.

\footnotetext{
${ }^{1}$ http://hellowaterside.northampton.ac.uk/
} 
In 2015, the University formed a partnership with the African Leadership College (ALC) ${ }^{2}$ to deliver a range of (mainly online) undergraduate programmes to that institution's new campus in Mauritius. To support this new initiative, a range of curriculum support opportunities for staff was introduced, building on earlier revisions of the Carpe Diem process. A range of flexible support options, with face-to-face workshops followed by online support and guidance and a peer-review process, was initially made available to staff involved in the ALC initiative and, subsequently, to all staff.

\section{Example 2}

At Northampton, CAleRO is integrated into our wider staff development programme as an option for developing learning and teaching practice. The teaching staff at Northampton come from diverse backgrounds and include those with many years of teaching experience as well as those fresh from graduate study or from industry. Not all of these have had opportunities for formal development in designing taught courses or in active and blended learning approaches, so the requirements of the curriculum change project have had considerable implications for staff development. To support this, the University introduced dedicated resources: currently, four full-time members of staff employed as 'Learning Designers', with a major part of their role focused on facilitation of CAleRO workshops.

CAleRO has also been embedded into our quality-assurance and enhancement processes. Engagement with the process is mandatory for validation of new modules and programmes and it is recommended as one of a suite of available quality-enhancement options for Periodic Subject Review.

\section{Analysis and evolution of the Carpe Diem model}

\section{Example 1}

Over the past year, a new 'Academic Quality and Development' department has been formed at GCU. As part of this restructuring, there has been a refocus of professional development opportunities, including a core focus on curriculum design. One of our initial actions was to implement a survey on the digital capabilities of academic staff, to establish a baseline for future CPD priorities. As part of this, we asked staff to rate their confidence levels in various aspects of designing and teaching online modules, including curriculum design. As shown in Figure 1, overall confidence levels were relatively low, with only $42 \%$ of respondents identifying themselves as highly, or very, confident in designing the curriculum for online modules. In all other aspects, including the design of online learning activities and assessments, results showed that the majority of respondents felt only slightly, or not at all, confident.

\footnotetext{
${ }^{2}$ https://www.gcu.ac.uk/theuniversity/international/alc/
} 


\section{Designing the curriculum for an online module}

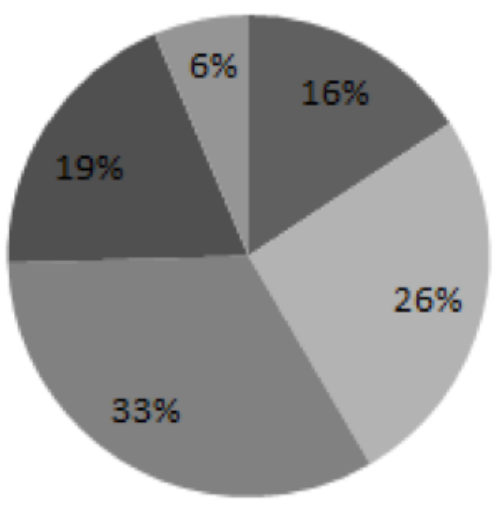

Highly

nery

- Slightly

Not at all

N/A

Figure 1: Staff confidence in designing and teaching online modules

The survey results informed the development of a Digital Learning Implementation plan which highlights curriculum design for blended and online programmes as a key priority for the University, providing justification for the further roll-out of the Carpe Diem curriculum design model.

Carpe Diem has been incorporated into an overarching learning design workflow which ideally starts with a face-to-face Carpe Diem full-day workshop. Owing to time pressure on staff, we have reduced the face-to-face session to two hours. Such a reduction of the workshop has been possible because our development of existing modules has fixed many of their design elements, including learning outcomes. For example, in the case of the ALC modules, the focus was on transposing existing campus-based content and activities to equivalent online ones. For most module teams, the main takeaway from the session has been a shared overarching module design in which key points of interaction include student activities, summative assessment and feedback opportunities.

Staff have been encouraged to use Trello (an online collaborative task-management tool) to convert their initial paper and post-it note storyboards into a working, collaborative online document. The uptake of Trello has surpassed initial expectations and has allowed staff not only to share new designs but also to provide a way to map other existing modules. ${ }^{3}$ Trello boards provide a simple, shareable view of a module design.

Once a Trello board is created and populated, prototyping of the course design begins. Initially, we had encouraged use of Coursesites, the open version of Blackboard, but, in practice, most module teams have either used a community area within our VLE or the

\footnotetext{
${ }^{3}$ http://edshare.gcu.ac.uk/3170/
} 
actual module shell. It is at this point that, in general, staff start to work with the Learning Technologists in their schools to develop learning activities and course content.

As part of the ALC project, all modules are required to go through a light-touch qualityenhancement process. To support this process, a peer-review checklist, based on an agreed set of characteristics and standards, has been developed. This has enabled subject specialists and the Academic Development team to review modules in terms of both the appropriateness of overall learning design, and core content and activities. The checklist has proved popular with academic colleagues, a number of whom have started to use it with other non-ALC modules.

At GCU, evaluation and review is linked to the University's existing module evaluation process. When required, we are able to adapt and extract relevant elements of the Carpe Diem process to focus on particular elements in a programme - for example, assessment and feedback, if that is what is required by a review process or highlighted as an area for development by a module team.

Over the academic year 2017/18, the Academic Development Team is working with Schools to offer a more structured approach to module/programme/curriculum design to support the University's aspirations for digital learning. We shall be working with nominated module teams as they design new programmes or refresh existing ones in blended and online mode. Working with the teams, we shall provide a range of flexible options, and shall have more opportunity to ensure that, from the outset, we are kept in the development loop.

\section{Example 2}

At Northampton, we have for the past four years been monitoring uptake and feedback from CAleRO participants and over that time we have made a number of adaptations to the original Carpe Diem workshop format. These are partly in response to continuing evaluation and feedback and partly to align the process more closely with institutional drivers, including the curriculum change project and our commitment to supporting staff to achieve professional accreditation through the Higher Education Academy (HEA). At UoN, we see CAleRO as having two outputs: a design for the module or programme and skills development for the teaching team.

In response to the diverse levels of experience among our teaching staff, we have discarded the original Carpe Diem requirement that learning outcomes must be finalised in advance of the workshop (Salmon and Wright, 2014). Some of our staff have little experience of writing effective learning outcomes, and getting these right is fundamental to the ensuing design, so we took the decision to address these, if necessary, within the workshop itself, before progressing to align the assessment and the learning and teaching activity. We also designed some independent learning activities directly into the CAleRO planner ${ }^{4}$, for staff who want to find out more in their own time about outcomes, assessment and the design of learning and teaching activities.

Staff and facilitator feedback revealed that different course teams had different needs and, as a result of this, we use the pre-CAleRO diagnostic ${ }^{5}$ to determine the agenda for the

\footnotetext{
${ }^{4}$ http://bit.ly/CAleRO-planner

5 http://blogs.northampton.ac.uk/learntech/2014/12/24/de-mystifying-the-caiero-the-pre-caiero-meeting/
} 
workshop. Rather than following all of the steps in every workshop, we consider them more as a toolkit: we work with the course team to identify which steps need to be covered in detail and customise the workshop plan accordingly. This increases ownership of the process and helps staff to feel it is a constructive use of time. Of course, it also helps if the tailored agenda means that we don't need to take up two full days, which can be difficult for teaching teams to set aside; however, if we do need two days (or sometimes more), the custom agenda makes it clear that it is needs-based.

Linked to this idea of tailoring, for some CAleROs we have moved away from the emphasis on e-tivities. Our active blended learning agenda presents different challenges for different staff, depending on their experience and confidence with teaching and technology. Where a member of staff is finding it more challenging to design active-learning activities for the classroom, we might leave aside the VLE and help them plan out their face-to-face activity instead - and then, often, the right tools to support this, as well as the work that needs to happen before and after it, become obvious.

Feedback from participants has always emphasised the value of collaboration in CAleROs. So, in addition to the course team workshops, we also offer 'CAleRO for Individuals' workshops, for staff who can't get together with their team but still want to be able to work on their own modules. This approach has some disadvantages, in that the structure of the workshop can't be customised and it doesn't address alignment between modules on the same programme, but it also has advantages: the collaborative element is maintained by bringing individuals from different teams together and, through discussion, they often find parallels in teaching practice that are independent of discipline and context.

Further to support the staff development aspect of CAleRO, we have also included specific reflection points in the process. The planner provides prompts to reflect before the session on available student and external examiner feedback and there are now steps, in the workshop itself, where staff are encouraged to document both their learning and the rationale for any changes they have decided to make. This is intended to help staff recognise the development of transferable skills and also provides both notes towards personal development-planning and evidence for fellowship applications and quality processes.

\section{Conclusions}

Carpe Diem is a proven, flexible and engaging method for developing both blended and fully-online courses at university level. As the two examples have illustrated, a level of customisation and contextualisation is necessary to ensure that the model accommodates individual institutional priorities. This naturally restricts the direct comparisons that can be drawn between the two approaches, as well as the possibilities for collaborative evaluation. However, in bringing these two examples together, we have also found some common benefits and challenges in implementing variations of Carpe Diem and we draw these out here, for the consideration of those planning to implement similar approaches.

Release of staff time to engage with the process has proved a challenge for both institutions. Whilst the authors acknowledge that the rationale for the original two-day model is sound, they have found it challenging to replicate in their current contexts. Having high-level 
institutional support for the process and integrating it into wider review processes can be helpful, although these are by no means a cure-all, as the responsibility for meaningful participation will always lie with the individual staff member. Our experiences have also shown that the majority of staff engage positively with the workshop element, but it can be challenging to maintain development momentum after the event. Use of collaborative online tools such as Trello can alleviate this somewhat, though schedules sometimes dictate that staff have to leave significant chunks of time between a workshop and actual activity development. These are issues that both institutions are looking to address in the future.

Carpe Diem can also be a powerful way of introducing the concepts of open educational resources (OERs) and open educational practice (OEP) (Armellini and Nie, 2013). At GCU, by embedding the concept of open education within the Carpe Diem process, we encourage colleagues to consider OERs and OEPs as an integral part of their own teaching practice. At UoN, we have integrated a number of additional design-related OERS into the CAleRO toolkit. Both institutions have continued the open ethos of the early Carpe Diem planner, which was originally released under a Creative Commons (CC) licence, by publishing our supporting resources, using CC licences both for $\mathrm{GCU}$ resources ${ }^{6}$ and for $\mathrm{UoN}^{7}$, and by supporting other institutions in turn to adapt and implement their own versions of the Carpe Diem method. As an example, the ELDeR learning design process at The University of Edinburgh was adapted in turn from the CAleRO process at Northampton (University of Edinburgh, 2017) and it is in the spirit of this continuing conversation and collaborative iteration process that we offer these reflections on our experiences.

\section{Reference list}

Armellini, A. and Aiyegbayo, O. (2010) 'Learning design and assessment with e-tivities.' British Journal of Educational Technology, 41(6), 922-935.

Armellini, A. and Nie, M. (2013) 'Open educational practices for curriculum enhancement.' Open Learning, 28(1), 7-20.

Conole, G., (2013) 'Designing for learning in an open world.' In: Spector, M. and Lejoie, S.P. (eds.), Explorations in the Learning Sciences, Instructional Systems and Performance Technologies. New York: Springer.

Conole, G. and Wills, S. (2013) 'Representing learning designs - making design explicit and shareable.' Educational Media International, 50(1), 24-38.

Dempster, J.A., Benfield, G. and Francis, R. (2012) 'An academic development model for fostering innovation and sharing in curriculum design.' Innovations in Education and Teaching International, 49(2), 135-147.

\footnotetext{
${ }^{6}$ http://edshare.gcu.ac.uk/1284/ and http://bit.ly/2zkBnZ3

${ }^{7}$ http://bit.ly/CAleRO-planner
} 
Salmon, G. (2013) E-tivities: The Key to Active Online Learning. 2nd ed. New York: Routledge.

Salmon, G., Jones, S. and Armellini, A. (2008) 'Building institutional capability in e-learning design.' ALT-J: Research in Learning Technology, 16(2), 95-109.

Salmon, G. and Wright, P. (2014) 'Transforming Future Teaching through Carpe Diem Learning Design.' Education Sciences, 4(1), 52-63.

The University of Strathclyde (2007) Re-Engineering Assessment Practices in Scottish Higher Education. Available at: http://www.reap.ac.uk/reap/index.html (Accessed: 30 October 2017).

The University of Edinburgh (2017) About ELDeR. Available at: https://www.ed.ac.uk/information-services/learning-technology/supporting-learning-andteaching/learning-design/about (Accessed: 27 October 2017).

Glasgow Caledonian University (2014) GCU Interim Open Educational Resources Policy. Available at: http://www.gcu.ac.uk/media/gcalwebv2/library/content/pdffiles/GCU-InterimOpen-Educational-Resources-Policy-Approved.pdf (Accessed: 27 October 2017). 